\title{
Hypercholesterolemia Risk Related to Consumption of Palm Oil Produced in Côte d'Ivoire
}

\author{
Béhibolo A. Yoboué ${ }^{1}$, Djedjro C. Akmel ${ }^{1}$, Zita EB. N'Goran-Aw ${ }^{1}$, Rémi K. Coulibaly ${ }^{1}$, Gnomblesson G. \\ Tiahou $^{2} \&$ Nogbou E. Assidjo ${ }^{1}$ \\ ${ }^{1}$ Institut National Polytechnique Houphouët-Boigny (INP-HB), Yamoussoukro, Côte d'Ivoire \\ ${ }^{2}$ Unit of training and medical research, Alassane Outtara University, Bouaké, Côte d'Ivoire \\ Correspondence: Béhibolo Antoinette Yoboué, Institut National Polytechnique Houphouët-Boigny (INP-HB), \\ Yamoussoukro, Côte d'Ivoire, BP 1313 Yamoussoukro, Côte d'Ivoire. E-mail: yobouebantoinette@gmail.com
}

Received: February 13, $2019 \quad$ Accepted: March 7, $2019 \quad$ Online Published: May 6, 2019

doi:10.5539/jfr.v8n3p93

URL: https://doi.org/10.5539/jfr.v8n3p93

\begin{abstract}
The purpose of this work is to determine the consumption pattern estimated from quantity and frequency of consumption of palm oil produced in Côte d'Ivoire in order to assess risk of hypercholesterolemia related to these oils. To achieve this objective, a cross - sectional survey was conducted with 417 randomly sampled people in seven district capitals of Côte d 'Ivoire. This investigation shows that average of crude and refined R1 and refined R2 palm oil consumed are $24.52 \mathrm{~mL}, 25.88 \mathrm{~mL}$ and $24.13 \mathrm{~mL}$ per person per day, respectively. In addition, datas on consumption frequency of different palm oils indicate that refined palm oils are most prevalent in population's dishes. Daily consumption frequency of crude and refined palm oils varies between $7.43 \%$ and $85.40 \%$. These oils contain $32.95 \%$ to $48.04 \%$ palmitic acid (hazard). For a bioavailability of $100 \%$ palmitic acid, the risk assessment for hypercholesterolemia indicates that $26.02 \%, 25.80 \%$ and $21.73 \%$ of surveyed populations ingest higher quantities of palmitic acid. Those are greater than the recommended rate Anses (National Agency for Food Safety, Environment and Labor) during consumption crude and refined palm oils. 26,020, 25,800 and 21,730 cases of increase in serum cholesterol per 100,000 inhabitants after consumption crude, R1 and R2 oils. Concerning a bioavailability of $11 \%$, risk of hypercholesterolemia is $0 \% ; 0.02 \%$ and $0.03 \%$ respectively for the consumers of crude, R2 and R1 palm oils. Hypercholesterolemia risk varies from the mode of consumption and oils types.
\end{abstract}

Keywords: hypercholesterolemia, palm oil, risk

\section{Introduction}

Fats play a crucial role in many processes related to cell survival, growth and differentiation. They constitute one of the main energy sources (900 kcal / $100 \mathrm{~g}$ ) for human consumption. In addition, fats are also carriers of vitamins, essential fatty acids and other minor constituents, beneficial to health (De Kock, Degreyt, Gibon \& Kellens, 2005; Lecerf, 2011).

Dietary oils are from vegetable and animal origin. Vegetable oils are originate from palm oil and derivatives, soybean, rapeseed, sunflower, cotton, peanut and olive oils. Indeed, palm oil is the vegetable oil the most produced and consumed worldwide (Battaglia, 2010; Jacquemard, 2011). It is a major component of food security in Asian and tropical countries due to palm climate adaptation capacity and oil productivity (Jacquemard, 2011). Palm oil is very popular in Africa and occupies a prominent place in people diet of. According to Food and Agriculture Organisation (FAO), Côte d'Ivoire is the second largest producer in West Africa with an estimated production of 370,000 ton in 2014 (Faostat, 2017).

Palm oil presents many nutritional advantages because of its macronutrients (unsaturated fatty acids $50 \%$, saturated fatty acids $50 \%$ ) and micronutrients (carotenoids, vitamin E, phytonutrients) composition (Lecerf, 2013). In addition, numerous studies related to palm oil qualitative description have shown its beneficial effects for humanity (Mondé et al., 2010; Selvaduray et al., 2012; Wong \& Radhakrishnan, 2012).

However, Go et al. (2014) and Sun et al. (2015) reported that there has been growing health concern about palm oil due to the link between saturated fatty acids, particularly palmitic acid, and coronary heart disease. Therefore, the imperative is to assess the health risk due to the consumption of palm oils. This paper deals with the 
quantitative assessment of the population's exposure to the hypercholesterolemia risk due to the consumption of different palm oils produced in Cote d'Ivoire. To achieve this, consumption survey on crude and refined palm oils was first conducted in seven (7) district capitals of Côte d'Ivoire. Next, a chemical analysis of palmitic acid content of these oils was performed. The exposure estimation model was analyzed by the Monte Carlo simulation method to determine hypercholesterolemia risk related to these oils. The knowledge level of exposure of the populations in Côte d'Ivoire will allow on the one hand to better control the impacts of the crude and refined palm oils on the health of the populations and on the other hand, to ensure the safety of these consumers.

\section{Methods}

\subsection{Equipment}

Material used in this study consisted of crude palm oil (traditionally produced) and refined one (produced by refining industries in Côte d'Ivoire). In addition, food survey tools such as photographs and questionnaire were used to collect information.

\subsection{Data Collection}

Studies were conducted from November 2016 to February 2017 in seven Côte d'Ivoire areas (Abidjan, Abengourou, Dabou, Daloa, Korhogo, Man and Yamoussoukro). These cities were chosen because they are areas of district capitals. They also describe the way in which crude and refined palm oils are consumed in urban areas in the North, South, Center, East and West of Côte d'Ivoire.

\subsection{Sampling}

Interviewed people was taken via a systematic random sampling technique and this number of respondents was 417 (Giezendanner, 2012). They were interviewed about their crude and refined oils consumption. Respondent's number chosen was proportional to its demographic size (quota sampling). Frequency and quantities consisted of men and women having at least 18 years old obtained using the following equation:

$$
\mathrm{N}=\mathrm{t}^{2} \times\left[\mathrm{p}(1-\mathrm{p}) / \mathrm{e}^{2}\right]
$$

With n: the size of the sample,

e: the margin of error ( $5 \%$ ),

t: the margin coefficient deducted from the confidence rate (1.96),

$\mathrm{p}$ : the proportion of the elements of the mother-population that has a given property (50\%).

In addition, crude and refined (brand R2 and R1) palm oil samples were collected from trading areas and near the resellers and producers of crude palm oil. A non-probability sampling method called "snowball" was used to collect the samples from these seven areas (N'Deye, 2001). In each area, $500 \mathrm{~mL}$ oils samples were taken from containers usually used for trading. The sample were wrapped in aluminum foil sheets and stored in a thermos shielded from light at temperature varying from $25^{\circ} \mathrm{C}$ to $30^{\circ} \mathrm{C}$ for transport and storage in laboratory (Johnston $\&$ Sabin, 2010).

\subsection{Questionnaire for Crude and Refined Palm Oils Coconsumption}

As part of this work, a questionnaire on the usual consumption of crude and refined palm oils was established. This questionnaire concerned frequency and quantities of palm oils consumption by respondents.

Frequency questionnaire is used to evaluate the usual consumption of certain foods. It consists of a food or foods list with associated consumption frequency categories (in number of times per day, per week, per month, etc.). Method used herein is Cade, Thompson, Burley, \& Warm (2002) one in which a respondent checks or ticks frequency that most closely approximates his usual consumption. Frequency list used in this investigation consisted of different frequency categories (never, at least once a day, once a week, two to three times a week, every two weeks, once a month). In addition, determination of quantities of palm oil consumed was made by asking respondents to either describe quantity of oil purchased and the price or, to identify from a list of photographs exhibiting different volumes of oil, one that comes closest to the amount commonly consumed.

\subsection{Fatty acid Profile}

Fatty acid composition was determined by analysis of fatty acid methyl esters using gas chromatography (GC) according to standard NF EN ISO 5508 (1995). This method involves extraction and esterification of fatty acids. For that, $20 \mathrm{mg}$ of oil fraction was solubilized in $1 \mathrm{~mL}$ of TBME (tert-butyl methyl ether). After stirring and filtration with a $0.45 \mu \mathrm{m}$ filter of, $100 \mu \mathrm{l}$ of filtered solution were put in insert. Then $50 \mu \mathrm{l}$ of TMSH $(0.5 \mathrm{M}$ 
trimethylhydroxide hydroxide in methanol) were added for more volatile fatty acids. Latter are identified by comparison of their chromatograms with those of pure controls analyzed under the same conditions. Chromatograph used is of the Varian type (varian CPG, Sydney, Australia), equipped with a flame ionization detector (FID).

\subsection{Exposure Estimation and Risk Assessment of Hypercholesterolemia Related to Palm Oil Consumption}

According to Codex Alimentarius definition, exposure estimation is quantitative and / or qualitative assessment of probable intake of hazards (biological, chemical, physical) from food. It consists of quantifying level of chemicals, microorganisms or toxins human populations, subgroups of population and individuals are exposed, in terms of magnitude, duration and frequency.

In this work, exposure assessment consisted of determining amount of palmitic acid ingested during crude and refined palm oils consumption. To define this exposure, amount of palm oil ingested distribution (Q), palmitic acid concentration distribution (C), and frequency of consumption (F) distribution of these oils were determined from investigations and chemical analyzes. Thus, exposure estimation was determined according to following equation:

$$
\mathrm{I}=\mathrm{C} \times \mathrm{Q} \times \mathrm{F}
$$

With: $\mathrm{I}=$ amount of distribution of palmitic acid ingested $(\mathrm{g}) ; \mathrm{C}=$ concentration distribution of palmitic acid in palm oils (g/ $100 \mathrm{~g})$;

$\mathrm{Q}=$ amount of distribution of palm oil ingested per person $(\mathrm{g}) ; \mathrm{F}=$ frequency distribution of consumption of palm oils $\left(\mathrm{d}^{-1}\right)$.

Data obtained from different distributions relating to variables $\mathrm{C}, \mathrm{Q}$ and $\mathrm{F}$ were resampled via Bootstrap method, which increased original sample size to 20,000. The quantity I of palmitic acid ingested as a function of C, Q and F was estimated using Monte Carlo simulation. In total, 1,500 iterations were performed. Each simulation is a numerical calculation corresponding to a possible situation, more or less probable, of a real system. Results of this simulation represent amounts of palmitic acid ingested during crude and refined palm oils consumption. Following Anses recommendations described by Guy-Grand, (2017), Recommended Nutritional Intake (RNI) in palmitic acid must not exceed $8 \%$ of 2,000 Kcal/day requirements of an adult. This RNI corresponds to a daily consumption of $17.78 \mathrm{~g}$ of palmitic acid. Thus, by reporting different amounts of palmitic acid ingested by individuals at threshold of RNI (17.78 g / day), two groups of consumers are distinguished. On the one hand, proportions of populations ingesting quantities of palmitic acid at doses lower than or equal to the threshold (17.78 g / day). They are not likely to increase their serum cholesterol levels after palm oils consumption of "Probability P1". This probability P1 is obtained by projecting limit dose of palmitic acid (17.78 g) on cumulative density function described by different iterations. On the other hand, we observe a proportion of populations in the event of probable increase of serum cholesterol level (case where ingestion of quantity of palmitic acid content in oils is greater than $17.78 \mathrm{~g} /$ day) " Probability P2 ". This probability describes risk of hypercholesterolemia related to the ingestion of palmitic acid contained in crude and refined palm oils. P2 is defined according to equation (3):

$$
\mathrm{P} 2=1-\mathrm{P} 1
$$

P1: Proportions of populations not subject to a probable increase of their blood cholesterol (hypercholesterolemia) after crude and refined (R1 and R2) palm oils consumption.

P2 "Risk": Proportions of populations with a probable increase of their blood cholesterol (hypercholesterolemia) after crude and refined (R1 and R2) palm oils consumption.

\subsection{Bioavailability of Palmitic Acid Due to Crude and Refined Palm Oils Consumption}

Berry, (2009) reported that all palmitic acid in palm oils is bioavailable as a result of their consumption.

Indeed, studies based on chronic consumption of saturated fatty acid by humans, precisely, mimicking the current dietary intake of palmitate, have shown same deleterious metabolic effects of palmitic acid consumption, regardless its position within triglycerides. More precisely, palmitic acid has the same digestibility, absorption rates and has the same effects on plasma lipid concentrations regardless its position (Berry, 2009).

However, according to May \& Nesarretnam (2014), bioavailability of palm oil palmitic acid is a function of this fatty acid position in triglyceride. In palm oil, $87 \%$ of fatty acids in position 2 are unsaturated (oleic acid and linoleic acid), whereas only $11 \%$ of palmitic acid are in position 2 . However, pancreatic lipase hydrolyzes fatty acids in positions 1 and 3, become free. They can form soaps in calcium presence. This reduces their absorption, while 2-monoglyceride persists, absorbed as such, and is therefore better bioavailable (May \& Nesaretnam, 
2014).

Thus, in this work, quantitative assessment of hypercholesterolemia risk related to ingestion of crude and refined palm oils palmitic acid consumed will consider both cases: On the one hand, assessment of hypercholesterolemia risk taking into account bioavailability of all $(100 \%)$ palmitic acid contained in red and refined palm oils produced in Côte d'Ivoire. On the other hand, estimation of hypercholesterolemia risk related to bioavailability of $11 \%$ palm oils palmitic acid.

\section{Results}

Assessment of hypercholesterolemia risk was defined by results obtained from consumption frequency, palm oil consumed quantities distribution and distribution of palmitic acid concentration in crude and refined oils.

\subsection{Frequency of Oils Consumption}

Different oils consumption frequencies are shown in Figure 1. Crude palm oil is less common in diet of ivestigated populations with $7.43 \%$ daily frequency. Majority of surveyed population $(49.26 \%)$ consumed crude palm oil at least once a month. Moreover, rafined palm oil R1 and R2 are most present in dishes of this population investigated. These people consumed on daily palm oils R1 and R2 respectively at $85.40 \%$ and $77.72 \%$.

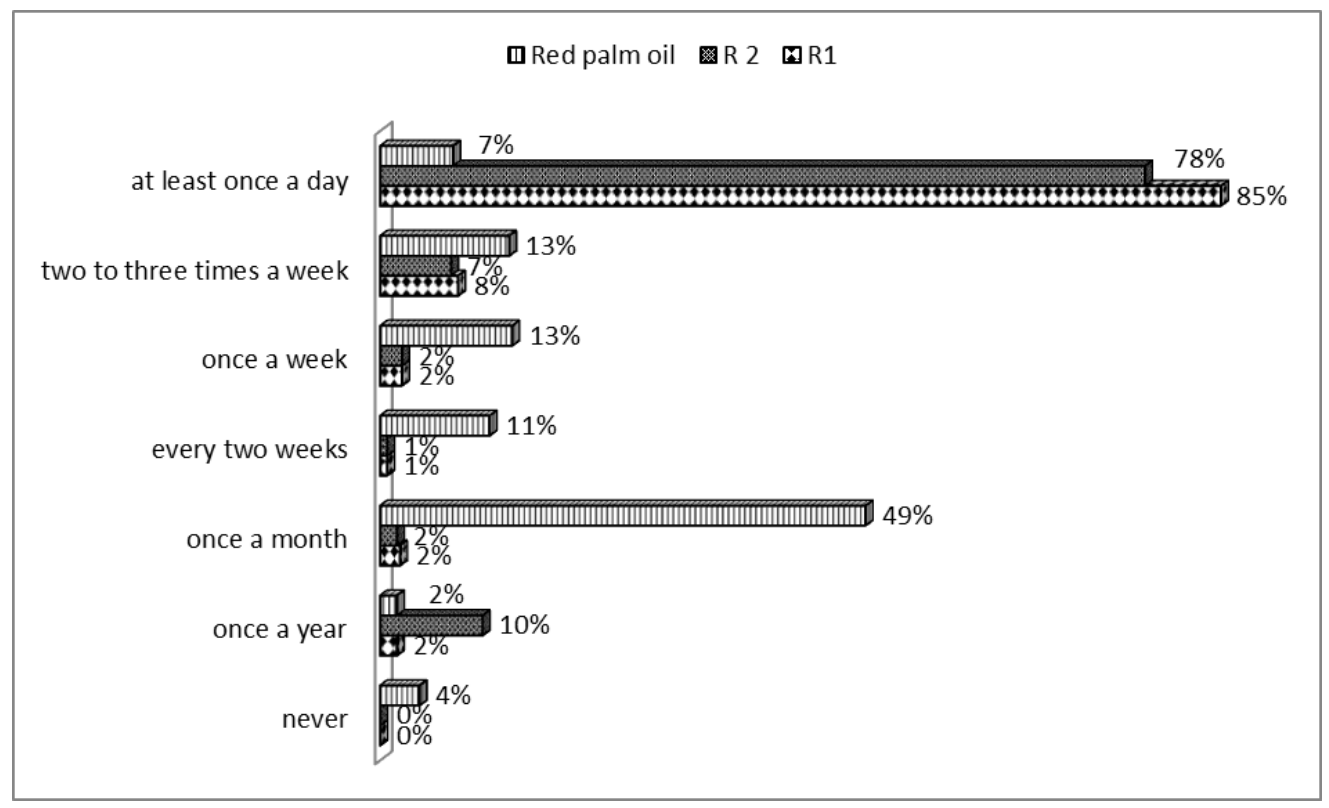

Figure 1. Frequency of crude and palm refined oils consumption

\subsection{Quantity of Oils Consumed}

Figure 2 depicts the distribution of crude and refined palm oil quantities consumed. Minimum daily quantities of crude and refined palm oils consumed by investigated population are in range from 0 to $30 \mathrm{~mL} /$ day. Maximum amounts are in a range from 90 to $125 \mathrm{~mL} /$ day. Quantities average consumed are between 23 and $25 \mathrm{~mL}$ per individual per day. 


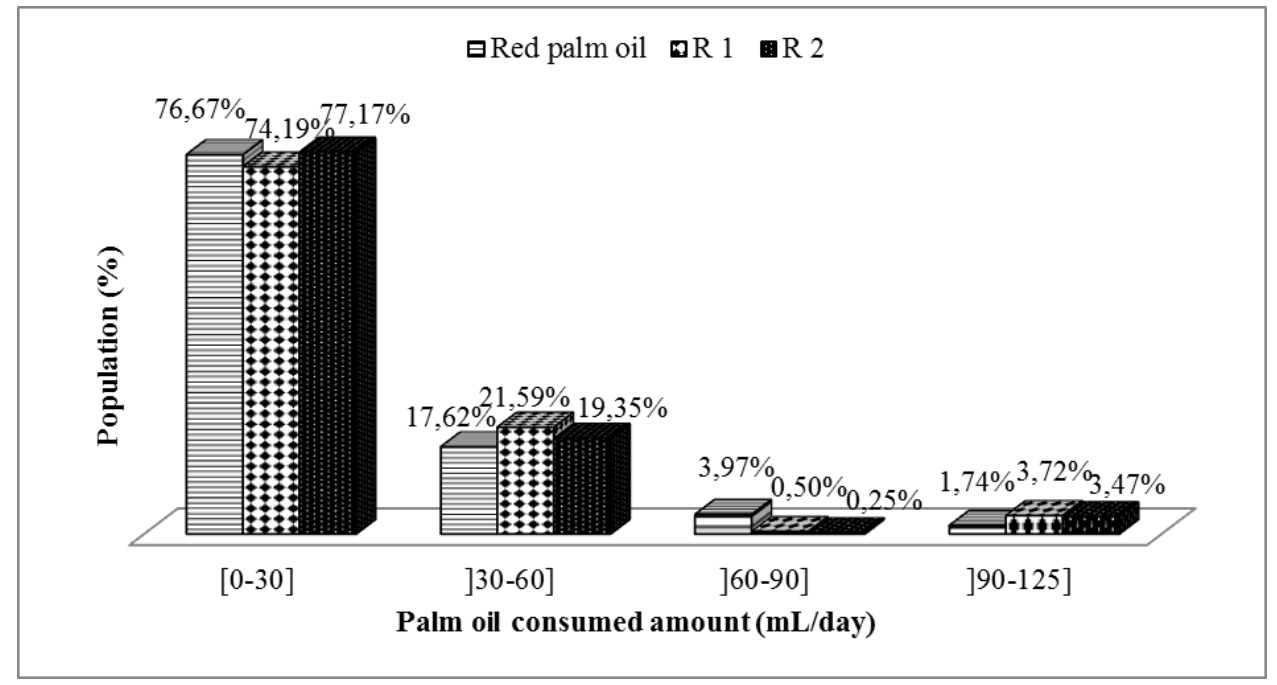

Figure 2. Distribution of crude and refined (R1 and R2) palm oils quantities consumed daily

\subsection{Fatty Acid Profile of Oils Samples}

Saturated Fatty Acid (SFA) and Unsaturated one (UFA) of crude and refined palm oils samples collected from different areas are listed in Table 1. Crude palm oils samples composition in saturated fatty acid and unsaturated one are ranges from 41.38 to $54 \%$ for SFA and from 46.00 to $58.62 \%$ for UFA. R1 and R2 palm oils contain percentages of SFA and UFA. For SFA, they are 41.54 and $41.21 \%$ for R1 and R2 respectively. Concerning UFA, values establish at 58.46 and $58.78 \%$. In addition, palmitic acid, which represents the chemical hazard studied, is present at levels ranging from 32.95 to $48.58 \%$ in artisanally produced crude palm oil. Palmitic acid contents varied from one locality to another. Thus, crude palm oil from Dabou contains the highest palmitic acid namely $48.58 \%$, while, samples from Man present the lowest value (32.95\%). Refined palm oils R1 and R2 contain respectively $35.29 \%$ and $34.98 \%$ palmitic acid.

Table 1. Fatty acid content of crude and refined palm oils

\begin{tabular}{|c|c|c|c|c|c|c|c|c|c|c|}
\hline \multirow[b]{2}{*}{ Cities } & & \multicolumn{6}{|c|}{ Crude palm oils } & \multicolumn{3}{|c|}{$\begin{array}{l}\text { refined palm } \\
\text { oils }\end{array}$} \\
\hline & & Abidjan & Daloa & Korhogo & Yakro & Abengourou & Man & Dabou & $\mathrm{R} 1$ & $\mathrm{R} 2$ \\
\hline \multirow{10}{*}{$\begin{array}{l}\text { FATTY } \\
\text { ACIDS }(\%)\end{array}$} & C14: 0 & 0.56 & 0.57 & 0.71 & 0.43 & 0.76 & 0.58 & 0.55 & 0.54 & 0.54 \\
\hline & Myristate & & & & & & & & & \\
\hline & C16:0 Palmitate & 34.74 & 37.04 & 37.41 & 34.38 & 39.66 & 32.95 & 48.04 & 35.29 & 34.98 \\
\hline & C16:1n-7c Palmitoleate & 0.08 & 0.11 & 0.1 & 0.07 & 0.12 & 0.07 & 0.11 & 0.11 & 0.12 \\
\hline & C18:0 Stearate & 6.97 & 5.55 & 6.91 & 8.18 & 5.15 & 7.39 & 5.02 & 5.24 & 5.22 \\
\hline & C18:1n-9c Oleate & 49.05 & 45.21 & 45.25 & 46.57 & 41.3 & 50.58 & 35.41 & 48.09 & 48.28 \\
\hline & $\mathrm{C} 18: 1 \mathrm{n}-7 \mathrm{c}$ vacenate & 0.48 & 0.41 & 0.51 & 0.42 & 0.66 & 0.5 & 0.65 & 0.65 & 0.67 \\
\hline & C18:2n-6c Linoleate & 7.38 & 10.4 & 8.36 & 9.08 & 11.56 & 7.19 & 9.55 & 9.61 & 9.72 \\
\hline & C18:3n-3 $\alpha$-Linolenate & 0.31 & 0.28 & 0.31 & 0.41 & 0.31 & 0.28 & 0.28 & - & - \\
\hline & C20:0 Arachidate & 0.43 & 0.43 & 0.44 & 0.45 & 0.48 & 0.46 & 0.39 & 0.47 & 0.47 \\
\hline \multirow{2}{*}{$\begin{array}{l}\text { TOTAL FATTY } \\
\text { ACIDS }(\%)\end{array}$} & AGS & 42.70 & 43.59 & 45.47 & 43.44 & 46.05 & 41.38 & 54.00 & 41.54 & 41.21 \\
\hline & AGI & $\mathbf{5 7 . 3 0}$ & 56.41 & 54.53 & 56.55 & 53.95 & 58.62 & 46.00 & 58.46 & 58.78 \\
\hline
\end{tabular}

\subsection{Risk of Hypercholesterolemia Linked to Consumption of Crude and Refined Palm Oils (Bioavailability of Palmitic Acid to 100\%)}

Figures 3, 4 and 5 show the ingestion probability as a function of the palmitic acid ingested amount for crude, R1 and R2 oils, based on the simulations results carried out by Monte Carlo method. This data consider a $100 \%$ of bioavailability of palmitic acid contained in crude, R1 and R2 oils. These figures show that proportions of populations that ingest palmitic acid quantities at doses less than or equal to the Recommended Nutritional Intake (RNI) during consumption of crude and refined R1 and R2 palm oils are respectively $73.98 \%, 74.20 \%$ and $78.27 \%$. These "positive" probabilities indicate that about $74 \%$ to $78 \%$ of populations in Côte d'Ivoire 
consume crude and refined palm oils at rational quantities respecting Recommended Nutritional Intake. But, $21.73 \%, 25.50 \%$ and $26.02 \%$ of this Ivorian population consume refined (R2, R1) and crude palm oils at doses exceeding Recommended Nutritional Intake.

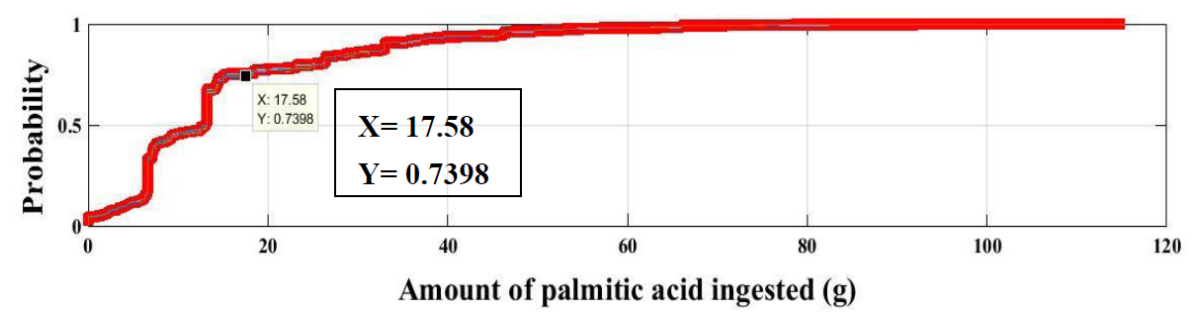

Figure 3. Risk of hypercholesterolemia at 100\% bioavailability of palmitic acid for crude palm oil

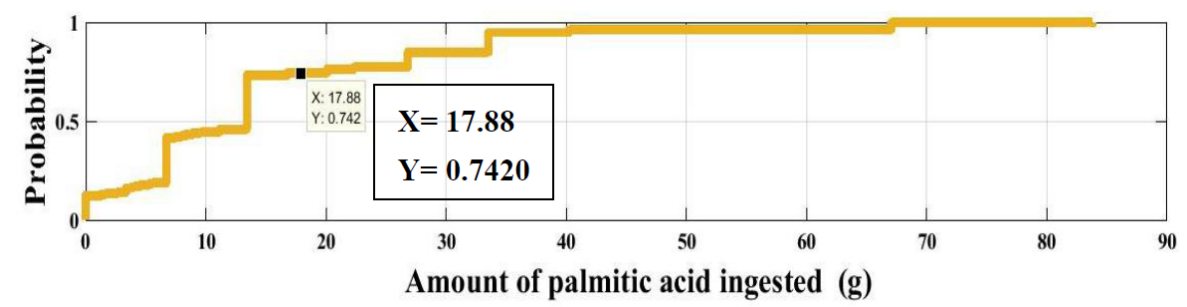

Figure 4. Risk of hypercholesterolemia at $100 \%$ bioavailability of palmitic acid for refined palm oil (R1)

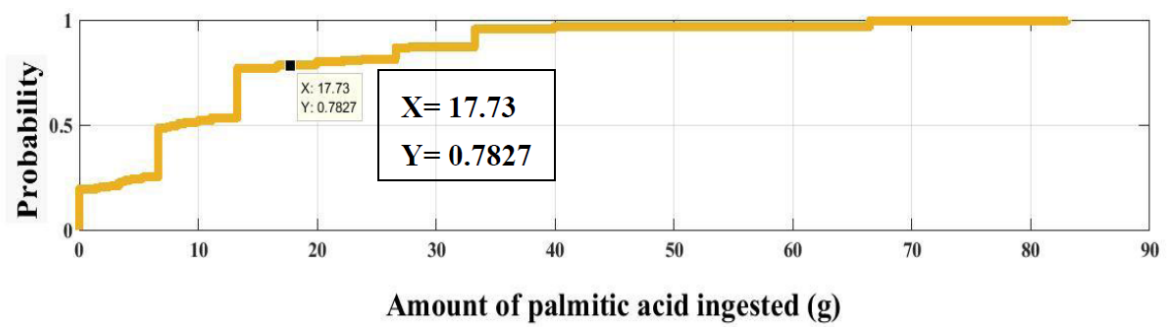

Figure 5. Risk of hypercholesterolemia at 100\% bioavailability of palmitic acid for refined palm oil (R2)

\subsection{Hypercholesterolemia Risk Related to Consumption Crude and Palm Refined Oil (Bioavailability of Palmitic Acid at $11 \%$ )}

In the same mood, Figures 6,7 and 8 describe hypercholesterolemia risk related to ingestion of palmitic acid contained respectively in crude and refined (R2 and R1) palm oils at $11 \%$ bioavailability. Considering that only $11 \%$ palmitic acids of crude and refined palm oils are bioavailable after their ingestion, hypercholesterolemia risk is very low for refined palm oils (R2 and R1) and is almost zero for crude palm oil.

Positive probabilities that is proportion of populations ingesting amounts of palmitic acid at levels less than or equal to the Recommended Nutritional Intake are $100 \%, 99.98 \%$ and $99.97 \%$ respectively for consumption of crude, R2 and R1 palm refined oils. These proportions indicate that per 100,000 people, representing the whole or 99,970 to 99,980 of these people will probably be not subject to increase in serum cholesterol levels after consumption crude, R2 and R1 refined palm oils. However, 20 to 30 people will be at risk of hypercholesterolemia after consuming these oils. 


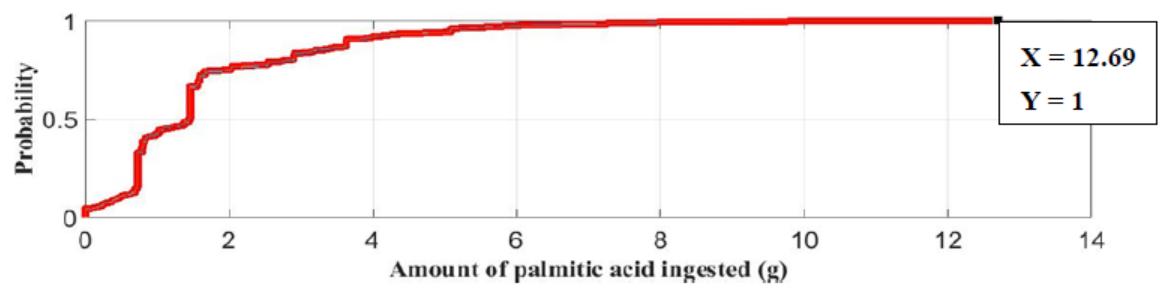

Figure 6 . Risk of hypercholesterolemia at $11 \%$ bioavailability of palmitic acid for crude palm oil

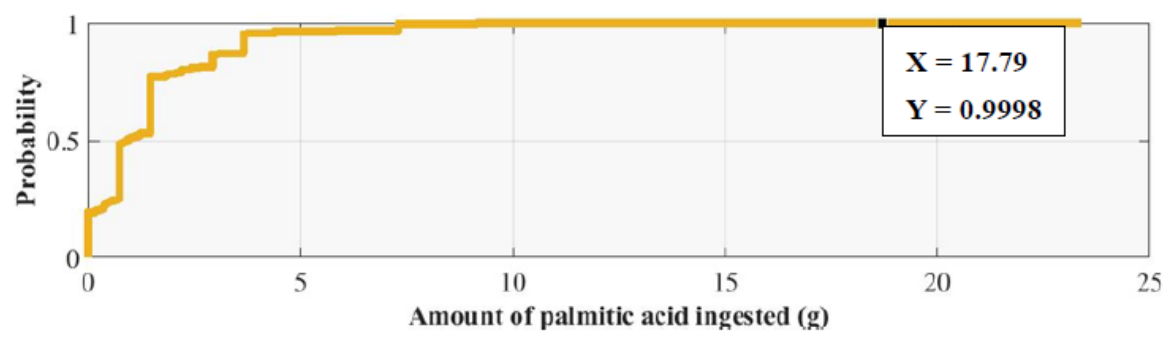

Figure 7. Risk of hypercholesterolemia at $11 \%$ bioavailability of palmitic acid for rafined palm oil (R2)

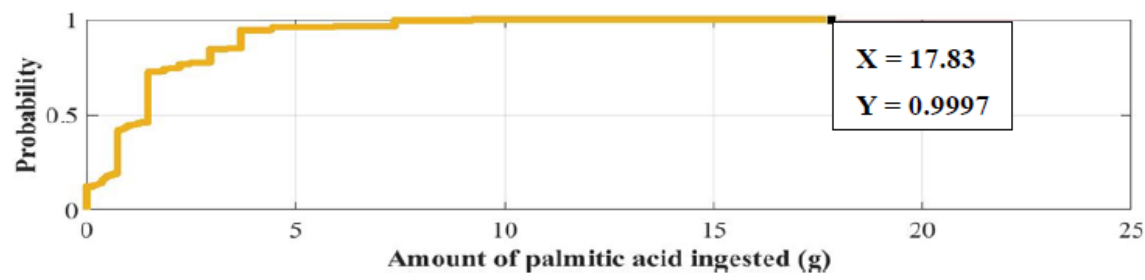

Figure 8. Risk of hypercholesterolemia at $11 \%$ bioavailability of palmitic acid for rafined palm oil (R1)

\section{Discussion}

Results of food surveys have shown that crude palm oil is less common in investigated populations diet. Indeed, daily frequency is only $7.43 \%$. This daily crude palm oil consumption frequency is lower than that observed in Congo, which is $11.4 \%$ (Moutoula, Mananga, Elenga, \& Kinkela, 2016). Most represented crude palm oil in investigated population is at least once a month, which is $49.26 \%$. This monthly consumption frequency of crude palm oil is similar to that observed in Yaoundé, Cameroon (approximately $44 \%$ per month) (Rebena, 2016). However, crude palm oil consumption frequency and that of Yaoundé seem to be lower than those of children from 6 to 36 months old in Benin. Nearly $70 \%$ of these children consume crude palm oil at least of once a week (Hounkpatin, 2011). Indeed, crude palm oil is an excellent vitamins A and E source (Morin \& Pagès-Xatart-Parès, 2012; Sen, Khanna, \& Roy, 2006). Regular consumption of this oil can cover consumer's nutritional needs including vitamins $\mathrm{A}$ and $\mathrm{E}$.

Moreover, refined oils (R1 and R2) are the most present in dishes of population investigated. These people consume R1 and R2 palm refined oils on a daily basis at $85.40 \%$ and $77.72 \%$, respectively. This daily consumption frequency for refined palm oil in Côte d'Ivoire reflects world demand since according to Guilaume-Gentil et al. (2016), palm oil is most produced and consumed vegetable oil in world over the last ten years (Guilaume-Gentil et al., 2016). Similarly, it is the cheapest food oil in world (Jacquemard, 2011), so accessible to all markets. In addition, refined oils are most used for frying food in Côte d'Ivoire (Cheyns, 2001).

Ditribution of crude and refined palm oil consumption quantity show that minimum amounts vary between 0 and $30 \mathrm{~mL}$ and maximum are between 90 and $125 \mathrm{~mL}$ per day. Most consumed quantities are those between 0 and 30 $\mathrm{mL}$ referring to $74.19 \%$ to $77.17 \%$ of studied population. The least consumed amounts range from 90 to 125 $\mathrm{mL}$ per day (1.74\% to $3.47 \%$ of population). The mean consumed quantities are between 23 and $25 \mathrm{~mL}$ per 
person per day. These average quantities are slightly lower than those consumed in Ghana as described by Ofosu-Budu and Sarpong (Ofosu-Budu \& Sarpong, 2013), saying that each individual in Ghana consumes between 30 and $33 \mathrm{~mL}$ of palm oil a day. In fact, the quantities of crude and palm refined oils consumed are the same within study population. In addition, refined palm oil consumed amount has decreased.

According to the work of Cheyns in 2001 (Cheyns, 2001) about Côte d'Ivoire people crude palm oil consumption, refined palm oils were consumed four times, in quantities than crude palm. Therfore, the cousumed quantity reduction of palm oil can be due to awareness campaigns on diseases risk related to a diet rich in oil including obesity, diabetes, high blood pressure and cardiovascular disease.

Regarding chemical analyses, saturated fatty acid (SFA) and unsaturated one (UFA) contents in studied artisanally produced crude palm oils ranged from $41.38 \%$ to $54 \%$ (SFA) and from $46.00 \%$ to $58.62 \%$ for UFA. These values are close to those reported by Mondé et al. in 2008 (Mondé et al., 2008), with SFA levels varying between $40 \%$ and $52 \%$ and from $48 \%$ to $60 \%$ for UFA. Nevertheless, this composition of SFA and UFA differs from that observed by N'goran et al. in 2017 (N'Goran et al., 2017) with lower proportions of SFA (34.8-39.3 \%) in crude palm oil collected in Côte d'Ivoire four districts. Also, UFA content (58.6-64.3\%) of these four areas is higher than that obtained in this work. This difference in saturated and unsaturated fatty acid content in artisanally produced edible crude palm oil is thought to be due to the variety of palm oil seeds used in production of these oils or to type of soil on which palms grow, and climate change. Indeed, according to Boyer's work in 2010 (Boyer, 2010) on vegetable oils, it appears that these are triglycerides, whose composition depends on plant nature, its growing conditions, soil and season. Likewise, R1 and R2 refined palm oils have more or less identical SFA and UFA contents. R1 palm refined oil contains SFA $41.54 \%$ and UFA $58.46 \%$. While R2 oil contains $41.21 \%$ and $58.78 \%$ respectively in SFA and UFA. These results are close to those obtained by Chatigre in 2014 (Chatigre, 2014). His work revealed that Dinor's (palm refined oil) contained $44.09 \%$ SFA and $55.91 \%$ UFA.

In addition, palmitic acid, which represents hazard studied, is present at levels ranging from $32.95 \%$ to $48.04 \%$ in artisanally produced crude palm oil. Dabou's crude palm oil has highest palmitic acid content with a value of $48.04 \%$. While, Man has the lowest one $(32.95 \%)$. These palmitic acid contents are close to those described by Lecerf with values ranging from $39.3 \%$ to $47.5 \%$ (Lecerf, 2013). Rafined palm oils R1 and R2 contain respectively $35.29 \%$ and $34.98 \%$ of palmitic acid. These results are close to those obtained by Chatigre in 2014 (Chatigre, 2014), which revealed the presence of $37.97 \%$ of palmitic acid in Dinor. Indeed, palmitic acid is a fatty acid that is part of cell membrane constituents. It assures very important roles in humans, namely, energetic expenditure, membrane elasticity and viscosity. It also carries fat-soluble vitamins such as vitamins A, D, E and K. Besides, it can cause LDL and HDL cholesterol levels increase after an excessive ingestion (Legrand, 2007; Seghier, 2014).

Moreover, probabilities indicate that about $74 \%$ to $78 \%$ of populations in Côte d'Ivoire consume crude and refined palm oil at rational quantities respecting recommended nutritional intake.

Comparing these probabilities to 100,000 inhabitants, we find that approximately $73,980,74,200$ and 78,270 consumers of oils in differents forms are not at hypercholesterolemia risky level. However, risk determination, that is, probabilities of serum cholesterol increases cases after palm oil consumption indicate that approximately $26.02 \% ; 25.50 \% ; 21.73 \%$ of populations investigated ingest quantities of palmitic acid greater than the rate recommended by Anses respectively for R1, R2 and crude palm oils. That represents 26,020, 25,800 and 21,730 cases for 100,000 inhabitants. Risk of hypercholesterolemia is high considering that palmitic acid of crude and refined palm oils produced and consumed by population in Côte d'Ivoire is $100 \%$ bioavailable. Nevertheless, precipitation of palmitic acid by formation of calcium soap (Lecerf, 2013) would lead to a reduction of palmitic acid bioavailable level which would reduce hypercholesterolemia risk due to palm oils consumption.

However, when palmitic acid bioavailability is get to $11 \%$, Positive probabilities that proportion of populations ingesting palmitic acid amounts at levels less than or equal to recommended nutritional intake are $100 \%, 99.98 \%$ and $99.97 \%$ respectively for consumption of crude, R2 and R1 refined palm oils. However, 20 to 30 people per 100,000 will be at hypercholesterolemia risk after consuming refined palm oil. Indeed, palm oil consumption impact on markers of cardiovascular risk (cholesterol especially), depends on several parameters such as quantities consumed, and nutritional context (linoleic acid and cholesterol content of diet, total lipid intake) (Lecerf, 2013). Also, it is related to consumption frequency and bioavailability of the hazard.

In conclusion, the fundamental role of oils in body is to provide fatty acids giving the necessary energy for good body functionning. But, ingestion of saturated fatty acids such as palmitic acid can lead serum cholesterol (LDL and HDL) increase. This hypercholesterolemia depends on various parameters, namely consumption frequency, 
palm oil quantity consumed, palmitic acid concentration in oils and its bioavailability.

\section{References}

Battaglia, M. (2010). Drowned in palm oil. The explosion of world demand. The world magazine No. 39, World Supplement No. 20336, pp. 14.

Berry, S. (2009). Triacylglycerol Structure and Interesterification of Palmitic and Stearic Acid-Rich Fats: An Overview and Implications for Cardiovascular Disease. Nutrition Reseach Review, 22, 3-17. https://doi.org/10.1017/S0954422409369267

Boyer, A. (2010). Design of new synthons derived from oleic acid: application to polyretane synthesis. Thesis of University of Bordeaux 1 doctoral school of chemical sciences, pp. 201.

Cade, J., Thompson, R., Burley, V., \& Warm, D. (2002). Development, Validation and Use of Food-Frequency Questionnaires. Health Nutrition, 5(4), 567-587. https://doi.org/10.1079/PHN2001318

Chatigre, K. O. (2014). Comparative study of oils of canele (Canarium schweinfurthii) and palm (Elaeis guineensis): physicochemical, biochemical and nutritional characterization. Thesis of Felix Houphouet-Boigny University, pp. 170.

Cheyns, E. (2001). Urban consumption of red palm oil in Côte d'Ivoire: what markets ?. Oilseeds, Fats, Lipids, 8, 641-5. https://doi.org/10.1051/ocl.2001.0641

De Kock, J., De Greyt, W., Gibon, V., \& Kellens, M. (2005). Recent Developments in Refining and Modification: Removal of Contaminants in Edible Oils and Reduction of Trans Fatty Acids. Oilseeds and fats, Crops and Lipids Journal, 12, 378-384. https://doi.org/10.1051/ocl.2005.0378

Faostat. (2017). faostat.fao.org, $1 \mathrm{p}$.

Giezendanner, F. D. (2012). Size of a Random Sample and Error Margin. pp. 1-22.

Go, R-E., Hwang, K-A., Kim, Y-S., Kim, S-H., Nam, K-H., \& Choi, K-C. (2014). Effects of Palm and Sunflower Oils on Serum Cholesterol and Fatty Liver in Rats. Journal of medicinal food, OO(0), 1-7. https://doi.org/10.1089/jmf.2014.3163

Guilaume-Gentil, A., S., Zhang, S. G., Yanchun, M., \& Branko, D. B. (2016). Palm Oil. United Nations conference on trade and development. pp. 21.

Guy-grand, B. (2017). Last minute. Dietary Nutrition book, 52(8), 1. https://doi.org/10.1016/S0007-9960(17)30029-9

Hounkpatin, A. W. (2011). Evaluation of the Potential for Covering Vitamin A Needs of Young Children from the Sauces accompanying Staple Food Consumed in Benin. Thesis of Montpellier 2 Sciences and Techniques University of Languedoc, pp. 266.

Jacquemard, J-C. (2011). the oil palm. Book, pp. 275.

Johnston L. G., \& Sabin, K. (2010). Sampling hard-to-reach populations with respondent driven sampling. Methodological Innovations Online, 5(2), 38-48. https://doi.org/ 10.4256/mio.2010.0017.

Lecerf, J. M. (2011). Vegetable oils: Particularities and usefulness. Medicine of Evil Metabolic, 5(3), 257-262. https://doi.org/10.1016/S1957-2557(11)70237-1

Lecerf, J. M. (2013). Palm Oil: Nutritional and Metabolic Aspects Role on Cardiovascular Risk. Oilseeds and fats, Crops and Lipids, 20(3), 147-159. https://doi.org/ 10.1684/ocl.2013.0507

Legrand, P. Fats: structure, functions, recommended dietary intakes. Dietary Nutrition book, 42, 7-12.

May, C., \& Nesaretnam, K. (2014). Research advances in nutritional palm oil. European Journal of Lipid Sciences. Technology, 116, 1301-15. https://doi.org/10.1016/S0007-9960(07)91234-1

Mondé, A. A., Michel, F., Carbonneau, M., Tiahou, G., Vernet, H., Duvernay-Eymard, B., ... Sess, D. (2008). Content fatty acids and antioxidants of Côte d'Ivoire palm oil. African Pharmacopoeia and Traditional Medicine, 15, 11-17.

Mondé, A. A., Carbonneau, M. A., Dabaté, S., Konan, E., Sess, D., \& Cristol, J. P. (2010). Effects of Palm Oil Polyphenol Extracts in the In Vitro Oxidation of LDL by Copper. Journal of Sciences Pharmacology Bilogy, $11(1), 47-56$.

Moutoula, B. E., Mananga, V., Elenga, M., \& Kinkela, T. (2016). Study of the eating habits of Brazzaville households with a view to combating vitamin A deficiency. Journal of Applied Biosciences, 97, 9174-9186. 
https://doi.org/104314/jab.v97i145

Morin, O., \& Pages-Xatart-Parès, X. (2012). Oils and vegetable fats: functional resources and nutritional interest. Oilseeds and fats, Crops and Lipids, 19(2), 63-75. https://doi.org/10.1051/ocl.2012.0446

N'Deye, A. K. (2001). Study of the chemical composition and quality of homemade vegetable oils consumed in Senegal. Thesis of Pharmacy, University Cheik Anta Diop of Dakar (Senegal), pp. 99.

N'Goran, K. D. V., Kouassi, K. A., Pohé, J., Angbo-Kouakou, M. E., Yéléhi, D., \& Adima, A. A. (2017). Geographical Indication of Palm Oil of" Man "(Mountain District-Ivory Coast): A Comparative Analysis of Physico-Chemical Properties and Profiles in Fatty Acids Of Some Ivory Coast Red Palm Oils. European Scientific Journal, 13(18), 373-385. https://doi.org/10.19044/esj.2017.v13n18p373

Ofosu-Budu, K., \& Sarpong, D. (2013). Growth of the Ghana Palm Oil Industry: Implications for Smallholder Farmers and Long-term Sustainability. In: Rebuilding Africa's Food Potential West, A. Elbehri (ed.), FAO / IFAD, 375-422.

Rebena, A. (2016). Consumption, perception and uses of the red oil of housewives and restorers of Yaounde, Graduation thesis for the ISTOM engineering diploma in international agro-development in Higher School of International Agro-Development of Yaounde, (Comeroun), pp. 104.

Selvaduray, K., A., Radhakrishnan, A. K., Kutty, K., \& Nesaretnam, K. (2012). Palm tocotrienols decrease levels of pro-angiogenic markers in human umbilical vein endothelial cells (huvec) and murine mammary cancer cells. Genes Nutrition, 7(1), 53-61. https://doi.org/10.1007/s12263-011-0223-0

Seghier, Y. (2014). Dietary Fatty Acids: The Lines Move !. Oilseeds and fats, Crops and Lipids, 12, 473-4.

Sen, C., Khanna, S., \& Roy, S. (2006). Tocotrienols: vitamin E beyond tocopherols. Life Sciences, 78(18), 2088-2098. https://doi.org/10.1016/j.lfs.2005.12.001

Sun, Y., Neelakantan, N., Wu, Y., Lote-Oke, R., Pan, A., \& Dam, R. M. V. (2015). Palm Oil Consumption Increases LDL Cholesterol Compared with Vegetable Oils Low in Saturated Fat in a Meta-Analysis of Clinical Trials ${ }^{1-3}$. The Journal of Nutrition, 145, 1549-58. https://doi.org/10.3945/jn.115.210575

Wong, R. S., \& Radhakrishnan, A. K. (2016). Tocotrienol research: Past into Present. Nutrition Review, 70(9), 483-490. https://doi.org/10.1111/j.1753-4887.2012.00512.x

\section{Copyrights}

Copyright for this article is retained by the author(s), with first publication rights granted to the journal.

This is an open-access article distributed under the terms and conditions of the Creative Commons Attribution license (http://creativecommons.org/licenses/by/4.0/). 